\title{
LANDASAN PEMIKIRAN IMPLEMENTASI SISTEM MANAJEMEN MUTU ISO 9001:2008 DI FITK UIN MALANG
}

\author{
Mulyono \\ e-mail: mulyonouin@gmail.com \\ UIN Maulana Malik Ibrahim Malang
}

\section{Abstract}

This study aims to examine the foundation of the implementation of ISO 9001: 2008 Quality Management System in improving the quality of learning in the Faculty of Tarbiyah and Teacher Training (FITK) UIN Maulana Malik Ibrahim Malang, the results can be summarized as follows: 1) Making the concept of "Ulul Albab" as a jargon that would be manifested in the form of an educational program under the umbrella of "Ulul Albab". 2) Realizing a scientific structure that integrates science and Islam with the Tree of Science Metaphor. 3) Trying to anticipate the challenges of higher education both on the national macro and global competition. 4) Realizing organizational health (organization health), to develop academic freedom, innovation, creativity and knowledge sharing. 5) Applying quality assurance consistently. 6) Determined to apply quality culture by implementing QMS ISO 9001: 2008 as international standard quality standard. 7) Implementing the International Quality Management System Organization for Standardization (SSNI ISO) 9001: 2008 to achieve the quality standard of education. 8) Conduct internal audit for continuous improvement of quality (continual improvement). 9) Anticipate various organizational changes at any time and periodic. 10) The ability of leaders to have the vision and confidence to realize his vision. 11) Making the values of the Qur'an (the concept of ihsan: doing better) as the cornerstone of the implementation of the quality management system. 12) Implement the main principles of the quality management system: "Write down what is done and do what is written". 13) Implement a systematic and continuous quality assurance system. 14) The purpose of quality assurance to ensure: compliance, certainty, and relevance. 15) Stipulate the quality points refer to the quality of UIN Maulana Malik Ibrahim Malang. 16) Determined to make quality assurance in academic service.

Keywords: Platform, Thought, QMS, Quality, Learning.

\section{Abstrak}

Penelitian ini bertujuan untuk mengkaji tentang landasan pemikiran implementasi Sistem Manajemen Mutu ISO 9001:2008 dalam meningkatkan mutu pembelajaran di Fakultas Ilmu Tarbiyah dan Keguruan (FITK) UIN Maulana Malik Ibrahim Malang, yang hasilnya dapat disimpulkan sebagai berikut: 1) Menjadikan konsep "Ulul Albab" sebagai jargon yang hendak dimanifestasikan dalam bentuk program pendidikan di bawah payung "Ulul Albab". 2) Mewujudkan struktur keilmuan yang mengintegrasikan sains dan Islam dengan metafora Pohon Ilmu. 3) Berusaha mengantisipasi berbagai tantangan pendidikan tinggi baik pada makro nasional maupun persaingan global. 4) Mewujudkan organizational health (kesehatan organisasi), untuk mengembangkan kebebasan akademik, inovasi, kreativitas dan knowledge sharing. 5) Menerapkan Quality assurance (jaminan mutu) secara konsisten. 6) Bertekad menerapkan budaya mutu dengan mengimplementasikan SMM ISO 9001:2008 sebagai standart mutu level international. 7) Mengimplementasikan Sistem Management Mutu Internasional Organisation for Standardisation (SSNI ISO) 9001: 2008 untuk meraih standar mutu pendidikan. 8) Melakukan audit internal untuk perbaikan mutu secara berkelanjutan (continual improvement). 9) Mengantisipasi berbagai perubahan organisasi dalam setiap waktu dan periodik. 10) Kemampuan pemimpin untuk memiliki visi dan 
kepercayaan diri untuk mewujudkan visinya. 11) Menjadikan nilai-nilai al-Qur'an (konsep ihsan: berbuat yang lebih baik) sebagai landasan implementasi sistem manajemen mutu. 12) Mengimplementasikan prinsip utama sistem manajemen mutu: "Tuliskan apa yang dikerjakan dan kerjakan apa yang ditulis". 13) Menerapkan sistem penjaminan mutu secara sistematis dan berkelanjutan. 14) Tujuan penjaminan mutu untuk menjamin: kepatuhan, kepastian, dan relevansi. 15) Menetapkan butir-butir mutu merujuk pada butir-butir mutu UIN Maliki Malang. 16) Bertekad melakukan penjaminan mutu dalam pelayanan akademik.

Kata-kata kunci: Landasan, Pemikiran, SMM, Mutu, Pembelajaran

\section{Pendahuluan}

Penelitian ini bertujuan untuk mengkaji tentang landasan pemikiran implementasi Sistem Manajemen Mutu ISO 9001:2008 dalam meningkatkan mutu pembelajaran di Fakultas Ilmu Tarbiyah dan Keguruan (FITK) UIN Maulana Malik Ibrahim Malang. Penelitian ini penting dilakukan untuk membangun pemahaman mengenai Sistem Manajemen Mutu (SMM) sesuai dengan ISO 9001:2008 yang implementasinya di Perguruan Tinggi. Dengan demikian penelitian ini menjadi sangat penting untuk peningkatan mutu dan daya saing bagi Perguruan Tinggi yang berkomitmen untuk menghasilkan layanan bermutu serta kinerja yang tinggi.

Pengelolaan pendidikan di level perguruan tinggi sebagai bagian dari sistem pendidikan tidak terlepas dari penyempurnaan perangkat-perangkat intern organisasinya. Dengan kata lain, pendidikan dalam semua level utamanya di lingkungan perguruan tinggi perlu berupaya meningkatkan mutu secara terus menerus. Kemampuan untuk mengelola dan mengembangkan pendidikan tinggi sudah harus menggunakan prinsip-prinsip manajemen yang modern yang berorientasi pada mutu. Peningkatan mutu sangat dibutuhkan untuk memperbaiki dan menyempurnakan kegiatan pendidikan sekaligus antisipasi perkembangan lembaga yang semakin besar untuk go-internasional, dan menyiapkan diri memasuki persaingan global. Untuk itu, pengembangan keunggulan yang mendapat pengakuan internasional terhadap mutu proses sebuah pendidikan menjadi sangat penting. Dalam manajemen pendidikan, dimana pelayanan merupakan faktor utama, dan di sisi lain, dapat juga dibandingkan dengan sebuah organisasi manufaktur, dimana komponen utamanya adalah mahasiswa (sebagai input) dan ilmu pengetahuan, serta hasil keluarannya (output) berupa lulusan yang bermutu (Wahab, 2009).

Dalam era globalisasi saat ini dunia Perguruan Tinggi dituntut untuk menjaga dan meningkatkan mutunya. ISO 9001:2008 sebagai persyaratan standar sistem manajemen mutu dapat dijadikan acuan untuk mendesain dan mengembangkan Sistem Penjaminan Mutu Perguruan Tinggi. Standar ISO 9001:2008 sangat membantu dalam penetapan standar mutu, implementasi, evaluasi, perbaikan secara berkelanjutan. Dengan demikian Perguruan Tinggi dapat secara berkelanjutan dan konsisten menghasilkan lulusan yang memenuhi persyaratan pengguna lulusan dan perundang-undangan serta peraturan dan perundang-undangan serta peraturan yang berlaku (http://umm.tp.ugm.ac.id, 2016).

Fakultas Ilmu Tarbiyah dan Keguruan UIN Maulana Malik Ibrahim Malang (FITK UIN Maliki Malang) merupakan salah satu Fakultas di lingkungan UIN Maliki Malang yang telah menerapkan Sistem Manajemen Mutu (SMM) ISO 1900:2000 sejak tahun 2008 yang sekarang telah berkembang menjadi ISO 1900:2008. Dengan menerapkan Manajemen Mutu ISO 1900:2008 tersebut, maka FITK UIN Maliki Malang 
bertekad untuk mengedepankan mutu dalam setiap proses yang terjadi dalam setiap pelayanan akademik, yang telah disusun dalam Standar Mutu mulai dari input, proses maupun outputnya. Standar yang ditetapkan oleh FITK UIN Maliki Malang merupakan standar yang digunakan secara nasional, hanya saja ada beberapa muatan-muatan integrasi yang merupakan pembeda antara FITK UIN Maliki Malang dengan fakultas-fakultas di berbagai perguruan tinggi lainnya.

Berdasarkan latar belakang di atas maka fokus penelitian ini adalah: bagaimana landasan pemikiran implementasi Sistem Manajemen Mutu ISO 9001:2008 dalam meningkatkan mutu pembelajaran di Fakultas Ilmu Tarbiyah dan Keguruan (FITK) UIN Maulana Malik Ibrahim Malang.

\section{Metode Penelitian}

Penelitian ini menggunakan paradigma alamiah (naturalistic paradigm) dengan jenis pendekatan kualitatif model studi kasus (case study). Penelitian kualitatif yang dimaksud seperti yang diungkap Denzin dan Lincoln (1994) bahwa: “... qualitative researchers study things in their natural settings, attempting to make sence of, or interpret, phenomena in terms of the meanings people bring to them."

Desain penelitian berkembang selama proses penelitian berlangsung. Dengan penelitian kualitatif, peneliti menilai bahwa landasan pemikiran implementasi Sistem Manajemen Mutu ISO 9001:2008 dalam meningkatkan mutu pembelajaran di Fakultas Ilmu Tarbiyah dan Keguruan (FITK) UIN Maulana Malik Ibrahim Malang adalah tindakan yang manusiawi, karena setiap pelaku sebagai makhluk berkesadaran, yang tindakan-tindakannya bersifat intensional, melibatkan interpretasi dan pemaknaan.

Teknik pengumpulan data dilakukan dengan menggunakan tiga pendekatan, yaitu: (1) wawancara mendalam (indepth interviewing), (2) pengamatan (observation), serta (3) dokumentasi. Sedangkan teknik analisis data menggunakan model analisis data interaktif seperti yang dikembangkan oleh Miles dan Huberman (1992). Analisis data berlangsung secara simultan yang dilakukan bersamaan dengan proses pengumpulan data, dengan alur tahapan: (1) pengumpulan data (data collection), (2) reduksi data (data reduction), (3) penyajian data (data display), dan (4) kesimpulan atau verifikasi (conclution drawing \& verifying). Teknik analisis data model interaktif tersebut dapat dibagankan sebagai berikut:

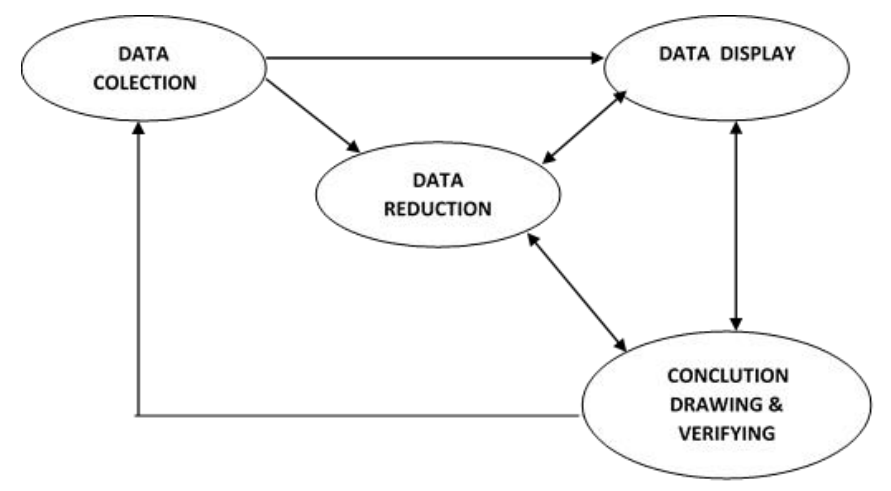

Gambar: Teknik Analisis Data Model Interaktif (Sumber: Miles dan Huberman, 1992:14)

\section{Temuan dan Pembahasan}

Pokok-pokok pikiran yang dapat ditemukan tentang landasan pemikiran implementasi sistem manajemen mutu ISO 9001:2008 dalam meningkatkan mutu pembelajaran di FITK UIN Maulana Malik Ibrahim Malang dengan merujuk pada implementasi Sistem Manajemen Mutu (SMM) di UIN Maliki Malang, dapat ditemukan sebagai berikut:

Pertama, FITK UIN Maliki Malang menjadikan "Ulul Albab" sebagai jargon yang hendak dimanifestasikan dalam bentuk program pendidikan, sehingga seluruh Fakultas, Jurusan dan program studi yang dikembangkannya berada di bawah payung "Ulul Albab". Profil Ulul albab yang dicita-citakan FITK UIN Maliki Malang adalah calon-calon lulusan yang memiliki kekokohan akidah dan kedalaman spiritual, keagungan akhlak, keluasan ilmu, dan kematangan profesional.

Kedua, untuk menghasilkan lulusan yang berpredikat Ulul Albab maka FITK UIN Maliki Malang merujuk pada konsep keilmuan UIN Malang menyusun bangunan struktur keilmuan yang 
disebut integrasi sains dan Islam dengan metafora Pohon Ilmu yang kokoh dan rindang serta memiliki akar yang teguh menghujam ke bumi, sebagai lambang universalitas ajaran Islam.

Ketiga, FITK UIN Maliki Malang berusaha mengantisipasi berbagai tantangan pendidikan tinggi pada umumnya, yang pada intinya menyangkut masalah-masalah sebagai berikut: (1) permasalahan makro nasional, yang menyangkut krisis ekonomi, politik, moral, budaya, dan sebagainya; (2) diberlakukannya globalisasi dan perdagangan bebas, yang berarti persaingan alumni dalam pekerjaan semakin berat; (3) Hasil berbagai lembaga survey tentang SDM, seperti Human Development Index (HDI, 2001, 2004), Asia Week (2000), dll. bahwa mutu pendidikan di Indonesia masih rendah; (4) angka pengangguran lulusan Perguruan Tinggi (PT) semakin meningkat; (5) tenaga asing meningkat, sedangkan tenaga Indonesia yang dikirim ke luar negeri pada umumnya nonprofessional; (6) orang-orang lebih senang sekolah atau menyekolahkkan anaknya di luar negeri; (7) peran PT dalam membentuk masyarakat madani (civil society).

Keempat, untuk mewujudkan FITK UIN Maliki Malang sebagai organisasi yang mampu melahirkan lulusan yang berkualitas maka diperlukan organizational health (kesehatan organisasi), yakni kemampuan Fakultas dan Universitas untuk mengembangkan kebebasan akademik, inovasi, kreativitas dan knowledge sharing. Salah satu komponen Fakultas dan Universitas yang sehat adalah adanya Quality assurance (jaminan mutu) dari perguruan tinggi yang bersangkutan. Untuk memperkokoh jaminan mutu tersebut maka UIN Maliki Malang telah mendeklarasikan implementasi Sistem Manajemen Mutu (SMM) ISO 9001:2000 sebagai tonggak sejarah bahwa seluruh sivitas akademika termasuk FITK harus berkomitmen untuk menerapkan SMM ISO 9001:2000 secara konsisten, pada tanggal 25 September 2008 yang kemudian dilanjutkan dengan implementasi SMM ISO 9001:2008.
Kelima, FITK sebagai elemen utama UIN Maliki Malang bertekad dengan semangat budaya mutu dengan mengimplementasikan SMM ISO 9001:2008 sebagai standart mutu level international, maka cita-cita menjadikan fakultas dan universitas unggulan (excellent university) segera terwujud dalam rangka menyajikan layanan prima bagi semua pihak, baik tingkat regional, nasional dan international. Main Audit bertujuan untuk mengukur kelayakan manajemen FITK dan UIN Maliki Malang dalam implementasi SMM ISO 9001:2008 sesuai dengan visi dan misi yang dicanangkan, sehingga layak menerima Sertifikat SMM level Internasional.

Keenam, Sistem Management Mutu Internasional Organisation for Standardisation (SSNI ISO) 9001: 2008. Standar SSM ISO 9001: 2008 adalah salah satu versi terbaru tahun 2008 yang merupakan kelanjutan versi 2000 yang berfungsi sebagai alat untuk meraih standar mutu pendidikan yang lebih baik serta untuk menunjukkan kinerja PT dengan memastikan agar dari waktu ke waktu senantiasa dapat menjamin eksistensinya sesuai dengan harapan stakeholdernya.

Ketujuh, melalui audit internal atau evaluasi diri ini, diharapkan FITK UIN Maliki Malang dan seluruh civitas akademika termotivasi memacu diri dalam melakukan pengembangan secara berkelanjutan (continual improvement) di masa-masa yang akan datang. Hal ini dilakukan guna meraih cita-cita bersama, yakni menjadikan FITK dan Universitas Islam Negeri (UIN) Maulana Malik Ibrahim Malang sebagai pusat keunggulan dan peradaban Islam (center of exelence and Islamic civilization) dimasa depan yang bertumpu pada empat kekuatan: (1) kekokohan aqidah dan kedalaman spiritual, (2) keluasan ilmu, (3) keagungan akhlaq, dan (4) kematangan professional.

Kedelapan, sebagai organisasi pendidikan tinggi yang bersifat terbuka dan dimanis, maka FITK UIN Maulana Malik Ibrahim Malang juga tidak terlepas dari berbagai permasalahan yang harus dihadapi sebagai tantangan yang bersifat intern maupun ekstern. Perubahan 
organisasi, pergantian pemimpin, perubahan sistem manajemen, dan perubahan-perubahan dari faktor-faktor eksternal merupakan perubahan yang dapat mengganggu keberlanjutan, mendistorsikan fokus, dan mengganggu keseimbangan antara faktor-faktor idealism dan realism. Disinilah kemudian diperlukan kemampuan pemimpin untuk memiliki visi, kepercayaan diri dalam menyelenggarakan semua komponen untuk bersama-sama mencapainya, menyediakan sumberdaya untuk dapat digunakan sebagai daya dorong dalam pencapaian visi, dan mendisiplinkan diri dalam "perjalanan panjang" pencapaian visi tersebut.

Kesembilan, sebagai Fakultas yang bernaung pada universitas yang berlandaskan nilai-nilai Islam, FITK UIN Maulana Malik Ibrahim Malang maka menjadikan nilai-nilai al-Qur'an sebagai landasan implementasi sistem manajemen mutu. Landasan konseptual nilai-nilai manajemen mutu dan penjaminan mutu dalam al-Qur'an dapat disarikan sebagai berikut: 1) Penjaminan mutu merupakan realisasi dari ajaran ihsan yakni berbuat baik kepada semua pihak disebabkan karena Allah telah berbuat baik kepada manusia dengan aneka nikmat-Nya, dan dilarang berbuat kerusakan dalam bentuk apapun (Q.S.alQashash: 77). 2) Seseorang tidak boleh bekerja dengan "sembrono" (seenaknya) dan acuh tak acuh, sebab akan berarti merendahkan makna demi ridla Allah atau merendahkan Tuhan. Maka hendaklah ia bekerja dengan baik (bermutu), dan hendaklah dalam beribadah kepada Tuhannya itu tidak melakukan syirk, yakni mengalihkan tujuan pekerjaan selain kepada Tuhan (a/- Haqq), yang menjadi sumber nilai intrinsik pekerjaan manusia. Dalam Q.S. al-Kahfi: 110. 3) Setiap orang dinilai dari hasil kerjanya (Q.S. al-Najm: 39), sehingga dalam bekerja dituntut untuk: (a) tidak memandang enteng bentuk-bentuk kerja yang dilakukan; (b) memberi makna kepada pekerjaannya itu; (c) insaf bahwa kerja adalah mode of existence (bentuk keberadaan) manusia; dan (d) dari segi dampaknya (baik/buruknya), kerja itu tidaklah untuk Tuhan, tetapi untuk dirinya sendiri (Baca Q.S. Fushshilat: 46; dan Luqman: 12). 4) Seseorang harus bekerja secara optimal dan komitmen terhadap proses dan hasil kerja yang bermutu atau sebaik mungkin, selaras dengan ajaran ihsan (Q.S. al-Nahl: 90). 5) Seseorang harus bekerja secara efisien dan efektif atau mempunyai daya guna yang setinggi-tingginya (Q.S.al-Sajadah: 7). 6) Seseorang harus mengerjakan sesuatu dengan sungguh-sungguh dan teliti (itqan), tidak separuh hati atau setengah-setengah, sehingga rapi, indah, tertib dan bersesuaian antara satu dengan lainnya. (Q.S. al-Naml: 88). 7) Seseorang dituntut untuk memiliki dinamika yang tinggi, komitmen terhadap masa depan, memiliki kepekaan terhadap perkembangan masyarakat serta ilmu pengetahuan dan teknologi, dan bersikap istiqomah (Q.S. al-Syarh: 7-8; al-Dluha: 4; al-'Alaq: 1-3; al-Syura: 15).

Kesepuluh, landasan Peraturan Pemerintah utama implementasi sistem manajemen mutu FITK UIN Maliki Malang adalah: Undang-Undang Nomor 20 tahun 2003 tentang Sistem Pendidikan Nasional Pasal 1 ayat 21, Pasal 35 ayat 1, Pasal 50 ayat 2, dan Pasal 51 ayat 2. Dan dalam Peraturan Menteri Agama No. 5/2005 tentang Statuta UIN Maliki Malang, terutama pasal 155 ayat (1) tentang Jaminan Kualitas penyelenggaraan pendidikan di UIN Maliki Malang.

Kesebelas, yang menjadi prinsip utama implementasi sistem manajemen mutu FITK UIN Maliki Malang adalah: "Tuliskan apa yang dilakukan/dikerjakan dan lakukan/kerjakan apa yang ditulis". Prinsip ini dikembangkan menjadi 8 (delapan) prinsip utama, yaitu: 1) Customer Focus (Fokus pada Pelanggan), 2) Leadership (Kepemimpinan), 3) Involvement of People (Melibatkan semua orang), 4) Process Approach (Pendekatan Proses), 5) System Approach to Management (Pendekatan Sistem pada Manajemen), 6) Continual Improvement (Peningkatan berkelanjutan), 7) Factual Approach to Decision Making (Pendekatan berdasarkan fakta untuk pengambilan keputusan), 8) Mutually Beneficial Supplier Relationship ((Hubungan yang saling menguntungkan dengan pemasok).

Keduabelas, sistem penjaminan mutu yang diterapkan di FITK UIN Maliki 
Malang adalah suatu upaya perbaikan sistematis dan berkelanjutan. Sistem ini mengakui bahwa mutu selalu dapat dikembangkan. Prosedur yang dikembangkan menjamin bahwa staf secara terus menerus mempertanyakan mutu proses dan produk, serta secara terus menerus pula berusaha memperbaikinya.

Ketigabelas, tujuan penjaminan mutu FITK UIN Maliki Malang adalah untuk memelihara dan meningkatkan mutu secara berkelanjutan, yang dijalankannya secara internal untuk mewujudkan visi dan misinya, serta untuk memenuhi kebutuhan stakeholders melalui penyelenggaraan tridharma perguruan tinggi. Penjaminan mutu FITK UIN Maliki Malang dilakukan untuk menjamin: 1) kepatuhan, 2) kepastian, 3) relevansi.

Keempatbelas, butir-butir mutu FITK merujuk pada butir-butir mutu UIN Maliki Malang yaitu setiap fakultas diharapkan dapat memilih dan menetapkan sendiri standar mutu pendidikan yang diselenggarakannya untuk tiap dalam sejumlah aspek yang disebut butir-butir mutu sebagai berikut: 1) Kurikulum Jurusan/Program studi; 2) SDM (dosen dan tenaga penunjang); 3) Mahasiswa; 4) Proses pembelajaran; 5) Proses pembinaan di Ma'had; 6) Prasarana dan sarana; 7) Suasana akademik; 8) Keuangan; 9) Penelitian dan publikasi; 10) Pengabdian kepada masyarakat; 11) Tata pamong (governance); 12) Manajemen lembaga (institutional management); 13) Sistem informasi; 14) Kerjasama dalam dan luar negeri.

Kelimabelas, FITK UIN Maliki Malang memahami bahwa sesuatu disebut bermutu apabila memenuhi: 1) Kesesuaian dengan standard; 2) Kesesuaian dengan harapan stakeholders; dan 3) Pemenuhan janji yang telah diberikan. Penjaminan mutu adalah: "proses penetapan dan pemenuhan standard mutu pendidikan secara konsisten dan berkelanjutan sehingga pelanggan atau stakeholders memperoleh kepuasan". Atau "proses yang digunakan untuk menjamin agar kualitas lulusan sesuai dengan kompetensi yang ditetapkan/dijanjikan serta dipertahankan secara konsisten dan ditingkatkan". FITK UIN Maliki Malang dapat dikatakan mencapai standar mutu apabila: 1) FITK UIN Maliki Malang mampu menetapkan dan mewujudkan visinya melalui pelaksanaan misinya (deduktif). 2) FITK UIN Maliki Malang mampu memenuhi kebutuhan stakeholders (induktif) berupa: a) societal needs (kebutuhan kemasyarakatan), b) industrial needs (kebutuhan dunia kerja), dan c) professional needs (kebutuhan professional).

Temuan penelitian tentang landasan pemikiran implementasi sistem manajemen mutu ISO 9001:2008 dalam meningkatkan mutu pembelajaran dapat dikaji melalui dasar pemikiran implementasi ISO 9001:2008. ISO 9001:2008 adalah suatu standar internasional untuk sistem manajemen mutu/kualitas yang menetapkan persyaratan - persyaratan dan rekomendasi untuk desain dan penilaian dari suatu sistem manajemen mutu. ISO 9001:2008 bukan merupakan standar produk, karena tidak menyatakan persyaratan- persyaratan yang harus dipenuhi oleh sebuah produk (barang atau jasa) namun merupakan standar sistem manajemen kualitas, sehingga dengan penerapan ISO 9001:2008, produk (barang dan/atau jasa) yang dihasilkan dari suatu sistem manajemen kualitas internasional, akan memiliki kualitas/standar yang baik. Dengan dimilikinya sertifikat ISO 9001: 2008 ini dapat menjadi salah satu added value yang saat ini menjadi kebutuhan organisasi untuk meningkatkan kualitas pelayanan kepada stakesholder-nya.

Penerapan ISO atau kebijakan mutu juga merupakan implementasi dari sejumlah regulasi untuk Perguruan Tinggi yang dikeluarkan oleh Pemerintah, yaitu antara lain UU No. 20 Tahun 2003 tentang Sistem Pendidikan Nasional, PP 19 Tahun 2005 tentang SNP (Standar Nasional Pendidikan), dan Surat Kopertis 3 No. 170/K.3/KL/2011 Tanggal 15 September 2011 mengimbau penerapan ISO 9001:2008 untuk meningkatkan tata kelola dan penjaminan mutu(Perbanas Institute, 20012). 
FITK UIN Maliki Malang, sebagai salah satu perguruan tinggi Islam terkemuka di Indonesia untuk mewujudkan visinya melahirkan tenaga pendidik dan kependidikan yang profesional, berdaya saing dan berkarakter Ulul Albab, salah satu strategi yang dilakukan adalah dengan penerapan ISO 9001: 2008 mengenai standar sistem manajemen kualitas. Dengan penerapan ISO 9001:2008 ini maka diharapkan output dari FITK UIN Maliki Malang yang dihasilkan dari suatu sistem manajemen kualitas berstandar internasional, akan memiliki kualitas/standar yang baik. Hal inilah yang ingin dicapai FITK UIN Maliki Malang yaitu untuk dapat memberikan layanan terbaik kepada seluruh stakes holder Fakultas, dengan mengambil sasaran kebijakan dan sasaran mutu: "Menuju Layanan Kelas Dunia". Manfaat dari penerapan ISO 9001:2008 bagi FITK UIN Maliki Malang antara lain: 1) Membuat sistem kerja dalam kampus menjadi standar kerja yang terdokumentasi dan mempunyai aturan kerja yang baik sehingga memudahkan pengendalian; 2) Menjamin bahwa proses yang dilaksanakan sesuai dengan sistem manajemen mutu yang ditetapkan; 3) Akan memudahkan Pimpinan dalam pencapaian target karena sudah dipersiapkannya target yang terukur dan rencana pencapaiannya; 4) Meningkatkan semangat dan moral pejabat dan karyawan karena adanya kejelasan tugas dan wewenang (job description); 5) Mengarahkan pejabat dan karyawan agar berwawasan mutu dalam memenuhi pelayanan dan permintaan pelanggan, baik internal maupun eksternal; 6) Untuk meningkatkan produktivitas, efisiensi, efektifitas operasional dan mengurangi biaya yang ditimbulkan karena pelayanan yang tidak sesuai; 7) Nilai kompetisi dan image positive dari Organisasi Fakultas baik sebagai lembaga pendidikan yang reputable maupun sebagai mitra kerjasama yang potensial dan strategis.

\section{Kesimpulan}

Berdasarkan fokus penelitian yaitu landasan pemikiran implementasi Sistem Manajemen Mutu ISO 9001:2008 dalam meningkatkan mutu pembelajaran di FITK UIN Maulana Malik Ibrahim Malang. Penelitian ini menggunakan metode kualitatif jenis studi kasus. Berdasarkan rumusan masalah, paparan data, temuan dan pembahasan, maka hasil penelitian ini dapat disimpulkan sebagai berikut: 1) Menjadikan konsep "Ulul Albab" sebagai jargon yang hendak dimanifestasikan dalam bentuk program pendidikan di bawah payung "Ulul Albab". 2) Mewujudkan struktur keilmuan yang mengintegrasikan sains dan Islam dengan metafora Pohon Ilmu. 3) Berusaha mengantisipasi berbagai tantangan pendidikan tinggi baik pada makro nasional maupun persaingan global. 4) Mewujudkan organizational health (kesehatan organisasi), untuk mengembangkan kebebasan akademik, inovasi, kreativitas dan knowledge sharing. 5) Menerapkan Quality assurance (jaminan mutu) secara konsisten. 6) Bertekad menerapkan budaya mutu dengan mengimplementasikan SMM ISO 9001:2008 sebagai standart mutu level international. 7) Mengimplementasikan Sistem Management Mutu Internasional Organisation for Standardisation (SSNI ISO) 9001: 2008 untuk meraih standar mutu pendidikan. 8) Melakukan audit internal untuk perbaikan mutu secara berkelanjutan (continual improvement). 9) Mengantisipasi berbagai perubahan organisasi antara lain: pergantian pemimpin, perubahan sistem manajemen, dan perubahan-perubahan dari faktor-faktor internal dan eksternal. 10) Kemampuan pemimpin untuk memiliki visi dan kepercayaan diri untuk mewujudkan visinya. 11) Menjadikan nilai-nilai al-Qur'an (konsep ihsan: berbuat yang lebih baik) sebagai landasan implementasi sistem manajemen mutu. 12) Mengimplementasikan prinsip utama sistem manajemen mutu: "Tuliskan apa yang dilakukan/dikerjakan dan lakukan/kerjakan apa yang ditulis". Prinsip ini dikembangkan menjadi 8 (delapan) prinsip utama implemntasi SMM, 13) Menerapkan sistem penjaminan mutu secara sistematis dan berkelanjutan. 14) Tujuan penjaminan mutu untuk menjamin: kepatuhan, kepastian, dan relevansi. 15) Menetapkan butir-butir mutu merujuk pada butir- 
butir mutu UIN Maliki Malang. 16) Bertekad melakukan penjaminan mutu dalam pelayanan akademik dengan memenuhi: a) Kesesuaian dengan standard; b) Kesesuaian dengan harapan stakeholders; dan c) Pemenuhan janji yang telah diberikan.

\section{Daftar Pustaka}

A. Azis Wahab, dan Dyah Kusumastuti, Refleksi Penjaminan Mutu/ Aplikasi Sistem Manajemen Mutu di Pendidikan. Bandung: Program S3 Administrasi Pendidikan UPI Bandung, 2009.

Administrator Perbanas Institute, Grand Launching Penerapan ISO 9001: 2008, Rabu, 11 April 2012, http://www.perbanasinstitute.ac .id/[Online] Sabtu, 5 Maret 2016.

Denzin, Norman K. \& Lincoln, Yvonna S. "Introduction: Entering the Field of Qualitative Research." In Norman K. Denzin and Yvonna S. Lincoln (Eds.) Handbook of Qualitative Research, Thousand Oaks: Sage Publications, 1994.

Fakultas Tarbiyah UIN Maulana Malik Ibrahim Malang, Pedoman Pendidikan Fakultas Tarbiyah. Malang: Fakultas Tarbiyah UIN Maulana Malik Ibrahim Malang, 2010.

http://umm.tp.ugm.ac.id/, Pelatihan Sistem Manajemen Mutu Perguruan Tinggi Berbasis ISO 9001:2008, [Online] Sabtu, 5 Maret 2016: 07.50.

M. B. Miles, \& A. M. Huberman, Penerjemah: Rohidi, T.R., Analisis data Kualitatif: Buku Sumber Tentang Metode-Metode Baru. Jakarta: UI Press, 1992. 